Wilfrid Laurier University

Scholars Commons @ Laurier

Psychology Faculty Publications

Psychology

3-1983

\title{
Primary Prevention: Another Perspective
}

Geoffrey Nelson

Wilfrid Laurier University, gnelson@wlu.ca

Harry Potasznik

Wilfrid Laurier University

Edward M. Bennett

Wilfrid Laurier University, ebennett@wlu.ca

Follow this and additional works at: https://scholars.wlu.ca/psyc_faculty

Part of the Psychiatry and Psychology Commons

\section{Recommended Citation}

Nelson, Geoffrey; Potasznik, Harry; and Bennett, Edward M., "Primary Prevention: Another Perspective" (1983). Psychology Faculty Publications. 23.

https://scholars.wlu.ca/psyc_faculty/23

This Article is brought to you for free and open access by the Psychology at Scholars Commons @ Laurier. It has been accepted for inclusion in Psychology Faculty Publications by an authorized administrator of Scholars Commons@ @aurier. For more information, please contact scholarscommons@wlu.ca. 


\title{
PRIMARY PREVENTION: ANOTHER PERSPECTIVE
}

\author{
GEOFFREY NELSON \\ HARRY POTASZNIK \\ and \\ EDWARD M. BENNETT \\ Wilfrid Laurier University
}

\begin{abstract}
This paper is a response to the British Columbia mental health planning report's position on primary prevention. The report adopts the position of Lamb and Zusman (1979) that research and service aimed at primary prevention should not be funded with money allocated for mental health, and arguments are presented to support this viewpoint. This paper critically reviews the ideological underpinnings, the research base, and the action implications of these arguments, and provides another paradigm for mental health policy in Canada. It is proposed that a spirit of open inquiry is needed so that alternative paradigms can be explored and innovations in both rehabilitation and primary prevention can be allowed to develop.
\end{abstract}

In May 1979, the British Columbia government released a report of a mental health planning survey team which was described as "the most extensive one undertaken in B.C." and that its recommendations "... will represent an important contribution to future policy." The B.C. report, which has been widely circulated in Canada, includes a reprint of an article by two U.S. psychiatrists, Drs. Lamb and Zusman, entitled "Primary Prevention in Perspective," The article was the survey team's statement regarding primary prevention.

The B.C. adoption of the Lamb and Zusman (1979) position on primary prevention has implications for mental health policy in Canada and therefore warrants a response. Lamb and Zusman (1979) assert that while primary prevention is currently a trendy, appealing concept, it suffers from definitional fuzziness and the lack of a sound research base. Moreover, they argue that there is a need to move beyond rhetoric to research documenting the effectiveness of primary prevention programs.
These criticisms are valid ones and have been acknowledged by advocates of primary prevention as challenges which must be addressed (e.g., Cowen, 1977, 1980. 1982). However, when considering the action implications of these assertions, Lamb and Zusman recommend a stance that is directly contrary to that espoused by the proponents of primary prevention research "... should be funded separately and with discretion" and that "scarce mental health funds should not be diverted from direct treatment for this purpose" (p. 12). Contrary to this viewpoint, Lalonde (1974) argued in his report on the health of Canadians that with escalating health care costs, some money may have to be diverted from direct treatment if Canada is to make any serious effort at lowering the incidence of mental health problems. Lamb and Zusman ignore the fact that the greatest advances in the field of health have consistently resulted from primary prevention, not medical treatment. They also fail to apply the same standards of proof to treatment programs. 
Canada's mental health system remains predominantly illness-oriented, hospitalbased, and focussed on individual treatment, yet there is little research evidence that this has been a fruitful approach in improving the mental health of Canadians.

The endorsement of Lamb and Zusman's position on primary prevention by the B.C. government reinforces the dominant mental health paradigm in Canada, while attempting to bury the alternative proposed by Lalonde and others. The purpose of this paper is to critically review the ideological underpinnings, the research base, and the action implications of the Lamb and Zusman paper. In so doing, an alternative paradigm for mental health policy in Canada is proposed.

\section{IDEOLOGY}

Lamb and Zusman present their arguments regarding primary prevention as if they are objective, verifiable scientific truths. To assert the null hypothesis that there is no evidence for primary prevention and to suggest that there probably never will be, except for some specific approaches, is simply not appropriate within the conventions of normal science. This type of reasoning could also lead one to abandon research on the causes of or interventions for cancer or any other health problem.

The arguments of Lamb and Zusman are steeped with ideological values and assumptions that are unexamined. In this section, we will examine the values and assumptions of Lamb and Zusman's position and those of the position they attack. This is an important first step because the research data that they selectively report and the action implications that they draw stem from their value base. Our goal is to challenge the dominant paradigm, represented by Lamb and Zusman, and to present an alternative. We do not intend to try to "prove" that one paradigm is "right" or "true" and that the other is "wrong" or "false". Prevention, early detection and treatment, and rehabilitation are all important, and one approach does not and should not preclude the other. We share Lamb and Zusman's concern for the need for effective programs for those with chronic mental health problems, but we feel that there are other priorities for the mental health of Canadians as well.

To help orient the reader to the arguments in this section, we have outlined tha values and assumptions of the traditional psychiatric model, espoused by Lamb and Zusman, and the community mental health model, which we are proposing as an alternative, in Table 1. First of all, the traditional model focusses on pathological behavior in the identified client and attempts to eliminate that behavior by treating the underlying cause.

With regard to etiology, Lamb and Zusman argue that heredity and organic deficits give rise to mental health problems in people. ".... Major mental illness is probably in large part genetically determined and is probably therefore not preventable, at most only modifiable (p.14)." Social environmental variables are regarded as uncertain in their causal relatedness to "mental illness." ". . . The cause and effect relationship between social conditions and mental, illness is extremely questionable (p.12)."

In terms of intervention, clinicians wait for client problems to develop and then treat the problem when some crisis has occurred and the client is in extreme need of assistance. Furthermore, an unstated implication of this model is that mental health services and research should be controlled by those most qualified to do organic treatment and basic research in etiology, medical personnel. Nowhere in their article is there a statement about the value of nonprofessional, citizens, or clients being involved in the control of mental health services. Finally, the political stance of the model is basically liberal. Gradual reform and progressive change within the system is encouraged, but becoming involved in political action to change social conditions is viewed as inap- 
Table 1

Values and Assumptions of the

Traditional Psychiatric Model and the

Community Mental Health Model

$\begin{array}{cc} & \begin{array}{c}\text { Traditional } \\ \text { Psychiatric Model }\end{array} \\ \text { Goals } & \begin{array}{c}\text { Treatment of mental } \\ \text { illness-pathology }\end{array} \\ \text { Etiology } & \begin{array}{c}\text { Heredity-organic } \\ \text { causality }\end{array}\end{array}$

Intervention

Stance

Professional

Role \& Service

Control

Political

Stance

\author{
Community \\ Mental Health Model \\ Promotion of mental \\ health-competence \\ Multiple causality: \\ person-environment \\ interaction \\ Active-preventive; \\ population focus \\ Collaborator-advocate; \\ Shared control
}

Social intervention propriate, ineffective, and outside of the jurisdiction of the professional.

In contrast to the traditional psychiatric model, the community mental health model focusses on the promotion of competence and health, both in persons and their environments. This involves teaching coping skills and strengthening environments to foster positive human growth (Albee, 1980; Bloom, 1979; Cowen, 1977; Moos, 1973). Thus, the community model emphasizes a social learning or developmental approach, rather than a defect approach.

The community model takes exception to the term "mental illness", and arguments, such as those of Lamb and Zusman, that one must differentiate between major "mental illness" and emotional distress. This is not to deny that mental health problems exist or that problems vary in level of severity. Rather, it reflects a concern about the increasing role of the medical profession as an agent for the social control of behavior that deviates from social norms. As Szasz (1960) has argued, "mental illness" does not exist, but it is a metaphor for describing deviant behavior. Labelling people with socalled "major and minor mental illnesses," such as the emotionally disturbed, delinquent, learning disabled, etc., encourages these people to view themselves as predestined sufferers of a "mental illness" which is not preventable and is therefore outside of their control and responsibility. The creation of negative stereotypes, with the potential that the labels will lead to a self-fulfilling prophecy, reinforces the dependency of the client on professional experts.

The community model acknowledges the contribution of genetic and organic factors to mental health problems, but emphasizes that no mental health problem can be caused, maintained, or meaningfully treated outside of a social and community context. Theorists who have reviewed the status of the major models of mental health problems have argued that each approach in isolation provides only a partial answer (Price, 1978; Zubin \& Spring, 1977). Alternatively, they have argued for a multifactor causal 
model. This approach is well represented by Albee's (1982a) equation:

$$
\text { Incidence }=\text { organic factors }+ \text { stress }
$$

coping skills + self-

esteem + support groups

Thus, the community model emphasizes that mental health or ill health is a function of the "fit" between the person and the environment (Rappaport, 1977).

In terms of intervention, the community model emphasizes a population and prevention focus. As Caplan (1964) outlined, prevention can be divided into primary (reduction of incidence), secondary (reduction of prevalence through early treatment), and tertiary (reduction of disability due to the problem) modes. Caplan highlighted the community as the main feature of all of these levels of prevention, with the overall goal of developing environments which foster in citizens an ability to adapt positively to the crises of daily living. A balance of these three levels of prevention is seen as desirable for mental health service and research, much as Clarence Hincks envisioned when he and others defined the goals of the Canadian Mental Health Association over 60 years ago.

\section{PRIMARY PREVENTION}

In contrast to the traditional model, the community model views mental health as a social issue which should not be left to the experts, but for which professionals, clients, and citizens must all be responsible. Working within the community framework, the professional is not in a superior role, but is a collaborator with and an advocate for citizens and clients. Control of the planning and delivery of mental health services and research is shared, so that citizens and clients learn to help themselves rather than be dependent on the expertise of scarce mental health professionals (Illich, 1976).

Finally, since social systems are not "neutral in their effects on people" but "contribute to or impair development" (Cowen, 1977, p. 7), the community model assumes that the mental health professional cannot be apolitical. If the social environment undermines the mental health of its citizens, the professional must become in volved in social intervention with others to reduce social and economic stress and to build support systems, coping skills, and self-esteem (Albee, 1981; Goldenberg, 1978). Advocacy on behalf of the poor and oppressed, the unemployed, and those with chronic mental health problems is essential since social conditions and mental health are strongly related.

\section{RESEARCH}

Having presented an alternative model to that of Lamb and Zusman, we will now briefly review some of the research literature pertinent to these two models.

Etiology. As Lamb and Zusman assert, research has documented the contribution of genetic factors to mental health problems. However, their contention of a largely exclusive role for genetic factors in the causation of mental health problems is an extreme position that is not widely shared even by genetic researchers (e.g., ErlenmeyerKimling, 1977). In an essay on the politics of nature and nurture, Albee (1982b) has argued that scientists tend to selectively attend to, report, and find evidence that is consistent with their political values. Thus, the more traditional, such as Lamb and Zusman, tend to find strong support for the nature position. To add more balance to their review, those of us who are more social change oriented can point to research indicating that there are multiple biological and environmental risk factors for adult schizophrenia (Zubin and Spring, 1977) and childhood mental health problems (Kornberg and Caplan, 1980; Rutter, 1979), supporting the multifactor viewpoint. Thus, genetic factors may not directly cause deviant behavior, but rather they may affect an individual's responsiveness to environmental stressors. For example, in a study of adopted children, Hutchings and Mednick (1974) found that a genetic predisposition (having a biological father who was a criminal) combined with environmental stress (having an adoptive father who was a criminal) to produce a high rate of criminal deviance in the children.

Lamb and Zusman glibly dismiss the importance of research relating social factors to mental health problems, arguing that the 
research is based on correlational findings. With insufficient knowledge of the causes of mental health problems, they argue that primary prevention should not be undertaken. The authors do not suggest that rehabilitation efforts be abandoned for the same reason. It is a fallacy to assert that prevention is not possible without knowledge of the causes of mental health problems (Caplan, 1964, pp. 29-30). Indeed, there is ample correlational evidence to suggest promising avenues for primary prevention, and controlled experiments in primary prevention may also help to reveal the causes of mental health problems.

A second problem with their argument about causality and social factors is that there exists stronger evidence than the authors suggest for a causal role for social factors in the etiology of mental health problems. While it is very difficult to conduct field research in which major social factors can be manipulated in an experimental fashion, there is evidence from longitudinal, quasi-experimental studies which indicates that environmental factors produce mental health problems. For example, Dohrenwend and Dohrenwend (1981) have used quasi-experimental strategies comparing advantaged and disadvantaged ethnic groups and have found evidence for the social causation of schizophrenia, personality disorders, and demoralization. Brenner (1973) has found strong correlations between economic downturns and hospitalization rates for mental health problems for the past century in New York state. More recently, Dooley and Catalano (1980) have reviewed studies demonstrating the causal role of economic changes in the development of mental health problems. A four year longitudinal study by Rutter, Maughan, Mortimore, and Ouston (1979) has implicated a causal connection between school atmosphere and juvenile delinquency and school maladaption. Other longitudinal studies (e.g. Thoits, 1982) have found that a supportive social network can prevent the development of mental health problems for those who are exposed to stressful life events. Finally, the more than 20 year longitudinal study of Leighton (1979) on social disintegration and mental health, which Lamb and Zusman refer to as a cross-sectional study, has shown significant improvement in the mental health of community members following local community development efforts and expanded external economic opportunities.

Intervention. No one would disagree with Lamb and Zusman that there is not enough evidence for primary prevention. However, the implication of this conclusion for us is that much more research is needed, whereas Lamb and Zusman seem to be calling for sharp limitations on such research. Thirty years ago, Eysenck (1952) argued that there was little evidence for the effectiveness of psychotherapy. No one at that time suggested that mental health services be abandoned. Rather, following Eysenck's controversial review, the field witnessed increasingly sophisticated documentation of the effectiveness of outpatient psychotherapy (Garfield and Bergin, 1978) and institutional (Paul \& Lentz, 1977) and community mental health rehabilitation programs (Stein \& Test, 1978).

In their review, Lamb and Zusman divide primary prevention programs into two categories: the "proven and probable", those which emphasize genetic counselling and organic intervention, and those of "doubtful value", those with a more environmental orientation (social competence training, child rearing, educational programs, crisis intervention, and social action). Attempting to suppress research on those programs which are incompatible with their model is blatantly political and is poor scientific practice.

While the current literature is limited, there is promising evidence for each of the primary prevention approaches which Lamb and Zusman argue will likely bear little fruit. One area which is growing at a fast 
rate is research on the promotion of social competencies. Spivack and Shure (1974) have shown in controlled studies that teaching social problem-solving skills to entire classes of pre-school children can effectively reduce the incidence of children labelled either impulsive or inhibited both at the end of the program and at a one-year follow-up. Their results have been partially replicated by others (Elardo \& Caldwell, 1979; Gesten, Rains, Rapkin, Weissberg, Flores de Apodaca, Cowen, \& Bowen, 1982). In terms of child rearing programs, the social problem-solving has been taught to parents and initial research has shown this to be another effective approach in reducing the labelled incidence of childhood mental health problems (Shure \& Spivack, 1978). Another longitudinal controlled study has demonstrated the effectiveness of an early parent-child intervention program in reducing the incidence of childhood behavior problems (Johnson \& Breckenridge, 1982).

In terms of educational prevention programs, some interventionists have attempted to develop healthy school and classroom atmosphere through organization development consultation. The pioneering work of Schmuck and his colleagues (Schmuck, Runkel, \& Langmeyer, 1969), which has since been replicated by others (Fullan, Miles, \& Taylor, 1980), has suggested that the mental health of students can be enhanced through such efforts in planned change.

Two recent controlled studies have documented the primary preventive effects of crisis intervention, self-help programs. Vachon, Lyall, Rogers, Freedman-Letofsky, and Freeman (1980) found that a self-help intervention for the population of recently widowed women in Toronto effectively reduced the incidence of mental health problems dealing with with the stress of losing a spouse through death. Bloom, Hodges and Caldwell (1982) obtained similar results in an evaluation of a prevention program for newly separated persons in Colorado. In terms of social action, the previously mentioned work of Leighton (1979) in Nova Scotia has suggested the primary preventive potential of community develoment and economic interventions.

In summary, there are clearly some promising beginnings for primary prevention programs which emphasize organic intervention and genetic counselling, discussed by Lamb and Zusman, and for programs which seek to change the social environment and develop competencies, discussed here. Most of the research on primary prevention in mental health has been conducted in the past 10 years. There are several indications that research in primary prevention is a fertile area: the appearance of three journals in the past two years which focus on prevention in menatl health (Journal of Preventive Psychiatry, Journal of Primary Prevention, and Prevention in Human Services); the annual Vermont conference on primary prevention, the proceedings of which are published; and the appearance of special issues of the American Journal of Community Psychology (1982) and Canada's Mental Health (1979) on primary prevention. To further these positive efforts, continued funding for research, service, and training is needed.

\section{ACTION IMPLICATIONS}

By advising that primary prevention research in mental health be funded with discretion Lamb and Zusman encourage the suppression of the fundamental values and logic of the scientific method: the exploration of alternative facts, hypotheses, and paradigms. It is essential to encourage and not suppress the merits of alternative approaches to the mental health of Canadians. Furthermore, it is important to recognize that the arguments of Lamb and Zusman are not based on scientific logic and fact but on the acceptance of certain values, which we have outlined. Their goal is to influence at a political level the funding of research and 
training programs which support their point of view and disregard others.

There are several action implications of exclusively adopting a traditional psychiatric model approach to mental health service, training, and research. Service programs and research review groups will be medically dominated, with legislated elimination of alternative viewpoints and competitors. The major proportion of training and research fellowships in mental health will be controlled by narrow factions within medical schools.

Is this a fantasy? We think not. A case illustration from one of the provinces indicates that the danger of the scenario described above is real. A recent external evaluation of a mental health funding body which will not be identified, can be paraphrased as follows:

1. the research advisory group restricted to members of the medical profession by legislation "runs a danger that policy regarding research priorities may become constricted."

2. the possibility was pointed out that "the composition of the committee determines the nature of the grants submitted."

3. "...several areas deemed to be of high importance (in the terms of reference of the government and research body) are notable for the lack of grant applications submitted: clinical investigations and intervention in high risk groups, delivery of care (including aftercare), and clinical innovation."

In other words, the possibility of systematic bias noted in this case example may be a direct function of constitutional arrangements which limit membership and content to the interests of a segment of a particular professional group. These dangers, which are far reaching and go beyond issues regarding the efficacy of primary prevention research, may arise from an endorsement of the Lamb and Zusman article for mental health policy. Lamb and Zusman endanger at the most fundamental level a value system of open inquiry and examination of alternative paradigms.

\section{SUMMARY AND RECOMMENDATIONS}

The primary purpose of this article was to challenge the arguments of Lamb and Zusman and to indicate the danger of their position for mental health policy in Canada. Policy derived from their article would exclude a comprehensive view of mental health problems and research and program alternatives.

In an historical study of the helping services, Levine and Levine (1970) found that services tend to be comprehensive and oriented towards prevention and social change during periods of economic prosperity and narrow and oriented towards individual treatment and preservation of the status quo during periods of economic deterioration. In a sense then, the Lamb and Zusman article is a reflection of the current political and economic climate. Thus, during the present difficult economic period, alternatives to the dominant traditional psychiatric model will encounter the resistance of those individuals and institutions who currently receive the lion's share of research and program funds.

Ironically, because of the high costs of health care, it is more important than ever to move towards a more comprehensive view of mental health problems and an examination of alternative paradigms. There is a need for collaboration and resource exchange (Gottlieb \& Schroter, 1978), rather than competition, protection of professional turf, and fragmentation. The interdisciplinary model suggested by the Federal-Provincial working group on mental health is a useful blueprint for mental health policy in Canada (Canada's Mental Health, March, 1977).

The following points can serve as guidelines for a Canadian mental health policy 
based on the alternative model that has been presented in this paper.

1. There is a need to establish a health paradigm such as the one proposed by Lalonde (1974). This paradigm would encourage a shift in program emphasis to include prevention and health promotion activities. as well as early treatment and rehabilitation programs.

2. There needs to be a concerted effort to alter the emphasis of training and research programs as well. A shift in the mental health delivery system will be difficult to accomplish unless this is done. Lamb and Zusman are correct in asserting that most mental health professionals are untrained in and have limited expertise in public education, social action, and interdisciplinary views of mental health. Training programs for new professionals and continuing education for experienced mental health professionals need to emphasize skill development in prevention, as well as more traditional approaches. Economic incentives to encourage retraining as well as a gradual redistribution of resources in budget categories should increase the motivation of individuals to acquire alternative ways of thinking and practicing.

3. Interdisciplinary research review groups need to be created. If the organizational and substantive affiliations of members were to be broadly defined, new research paradigms would emerge and the danger of being constricted by the systematic bias of interest groups and institutional affiliations would be dramatically reduced. Current practices almost guarantee policies and structural arrangements which by definition produce cronyism (members of many research committees are themselves recipients of grants from their own funding agency).

4. Minimum proportions of research funds should be distributed to diverse substantive areas such as basic research, prevention, and treatment. As well, a minimum proportion should be allocated towards interdisciplinary projects. The threat of competing interests would be reduced if new funds were allocated for new program categories.

5. There is a need to improve the relationships between research settings, such as universities, and service delivery systems. The integration of research and practice is critical for program development and evaluation and for scholarship. Evaluation research is needed for prevention and treatment programs alike. Resource exchange programs, such as the one initiated by the Wilfird Laurier University Psychology Department and the Waterloo County Board of Education, provide a cost-effective model which can enhance service delivery systems and provide opportunities for research in prevention and treatment. (Nelson, Bennett, Dudeck, and Mason, 1982).

6. Interdisciplinary programs should be encouraged to bridge the gap between basic and applied research. Multi-year funding should improve opportunities for teamwork between disciplines. Such programs include incentives and mechanisms for teamwork, or they will result in parallel rather than collaborative activities.

These guidelines for an alternative to the model presented by Lamb and Zusman. The community model encourages collaboration rather than competition between researchers and practitioners, between basic and applied research, between professionals and nonprofessionals, and between professionals from different disciplines, Also, the model stresses the need for policy, research, and practice to be comprehensive and integrative, rather than constricted and fragmented.

\section{RÉSUMÉ}

Le présent article se veut une réponse à la position adoptée par le rapport de planification sur la santé mentale en Colombie britannique à propos de 
la prévention primaire. Le rapport soutient les vues de Lamb et Zusman (1979) à l'effet que la recherche et les services orientés vers la prévention primaire ne devraient pas être subventionnés à même les fonds alloués à la santé mentale; il fournit des arguments pour soutenir ce point de vue. L'article fait la critique de l'idéologie sous-jacente, des fondements de la recherche et des implications pour l'action qui sont impliqués dans ces arguments; il propose un autre paradigme pour une politique de la santé mentale au Canada. On souligne le besoin d'un esprit d'ouverture pour explorer les différents paradigmes et pour permettre des innovations aussi bien pour la réhabilitation que pour la prévention primaire.

\section{REFERENCES}

Albee, G.W. A competency model to replace the defect model. In L. Bond \& J. Rosen (Eds.). Promoting competence and coping during adulthood: Primary prevention of psychopathology (Vol.4). Hanover, N.H.: University of New England Press, 1980.

Albee, G.W. Polities, power, prevention, and social change. In J.M. Joffe \& G.W. Albee (Eds). Prevention through political action and social change: Primary prevention of psychopathology. (Vol. 5). Hanover, N.H.; University of New England Press, 1981.

Albee, G.W. Preventing psychopathology and promoting human potential. American Psychologist, 1982, 37, 1043-1050. (a).

Albee, G.W. The politics of nature and nurture. American Journal of Community Psychology, 1982. $10,4-30$. (b).

American Journal of Community Psychology, 1982, 10 (3).

Bloom, B.L. Prevention of mental disorders: Recent advances in theory \& practice. Community Mental Health Journal. 1979, 15, 179-191.

Bloom, B.L., Hodges, W.F., \& Caldwell, R.A. A preventive intervention program for the newly separated: Initial evaluation. American Journal of Community Psychology, 1982, 10, 251-264.

Brenner, M.H. Mental illness and the economy. Cambridge: Haryard University Press, 1973.

Canada's Mental Health, Expert group on mental health, 1977, 25 (1), 3-6.

Canada's Mental Health, Issue on Primary Prevention and the Young Child, 1979, 27 (2).

Caplan, G. Principles of preventive psychiautry, New York: Basic Books, 1964.

Cowen, E.L. Baby-steps towards primary prevention. American Journal of Community Psychology, $1977,5,1-16$.

Cowen, E.L. The wooing of primary prevention. American Journal of Community Psychology. $1980,8,258-284$.
Cowen, E.L. Primary prevention research: Barriers, needs, and opportunities. Journal of Primary Prevention, 1982, 2, 131-137.

Dohrenwend, B.S., \& Dohrenwend, B.P. Socioenvironmental factors, stress, \& psychopathology. American Journal of Community Psychology. $1981,9,128-164$.

Dooley, D., \& Catalano, R. Economic change as a cause of behavioral disorder. Psychological Bulletin, $1980,87,450-468$.

Elardo, P.T., \& Caldwell, B.M. The effects of an experimental social development program on children in the middle childhood period. Psy. chology in the Schools, 1909, 16, 93-100.

Erlenmeyer-Kimling, L. Issues pertaining to prevention \& intervention of genetic disorders affecting human behavior. In G.W. Albee \& J.M. Joffe (Eds.). Primary prevention of psychopathology: The Issues. (Vol. 1). Hanover, N.H.: University of New England Press, 1977.

Eysenck. H.J. The effects of psychotherapy: An evaluation. Journal of Consulting Psychology, 1952, 16. 319-327.

Fullan, M., Miles, M.B., \& Taylor, G, Organization development in schools: The state of the art. Review of Educational Research, 1980, 50. $121-183$.

Garfield, S.L., \& Bergin, A.E. (Eds.). Handbook of psychotherapy \& behavior change: An empirical analysis (2nd edition), New York: John Wiley \& Sons, 1978.

Gesten, E. L., Rains, M., Rapkin, B.. Weissberg, R.P., Flores de Apodaca, Cowen, E.L., \& Bowen, R. Training children in social problemsolving competencies: A first and second look. American Journal of Community Psychology. $1982,10,95-115$.

Goldenberg, 1.1. Oppression and social intervention. Chicago: Nelson-Hall, 1978.

Gottlieb, B.H. \& Schroter, C. Collaboration and resource exchange between professionals and natural support systems. Professional Psychology, 1978, 9, 614-622. 
Hutchings, B., \& Mednick, S.A. Registered criminality in the adoptive \& biological parents of registered male adoptees. In S.A. Mednick et al. (Eds.). Genetics, environment. \& psychopathology. Amsterdam: North Holland, 1974.

Illich. I. Medical nemesis:. The expropriation of health. New York: Bantam Books, 1976.

Johnson, D.L., \& Breckenridge, J.N. The Houston parent-child development center and the primary prevention of behavior problems in young children. Americun Journal of Community Psychology, 1982, 10, 305-316.

Kornberg, M.S., \& Caplan, G. Risk factors \& preventive intervention in child psychotherapy: A review. Journal of Prevention, 1980, 1, 71-133.

Lalonde, M. A new perspective on the health of Canadians. Government of Canada, Ottawa, 1974.

Lamb, H.R., \& Zusman, J. Primary prevention in perspective. American Journal of Psychiatry. $1979,136,12-17$.

Leighton, D.C. Community integration \& mental health: Documenting social change through longitudinal research. In R.F. Munoz, L.R. Snowden, \& J.G, Kelly (Eds.). Social \& psy. chological research in community setrings. San Francisco; Jossey-Bass, 1979.

Levine, M., and Levine, A. A social history of helping services. New York: Appleton-Century-Crofts, 1970.

Moos, R.H. Conceptualizations of human environments. American Psychologist, 1973, 28, 652 665.

Nelson, G., Bennett, E.M., Dudeck. J., \& Mason, R.V. Resource exchange: A case study. Canadian Journal of Community Mental Health. $1982, I$, in press.

Paul, G.L., \& Lentz, R.J. Psychosocial treatment of chronic mental patients: Milieu vs. sociallearning programs, Cambrige: Harvard University Press, 1977.

Price, R.H. Abnormal behavior: Perspectives in conflict (2nd edition). New York: Holt-Rinehart-
Winston, 1978.

Rappaport, J. Community psychology: Values, research, \& action. New York: Holt, Rinehart, \& Winston, 1977.

Rutter, M. Protective factors in children's responses to stress \& disadvantage. In M.W. Kent \& J.E. Rolf (Eds.), Social competence in children: Primary prevention of psychopathology. (Vol. 3). Hanover, N.J.: University of New England Press, 1979.

Rutter, M., Maughan, B., Mortimore, P., \& Ouston, J. Fiffeen thousand hours: Secondary schools \& their effects on children. Cambridge, Mass:: Harvard University Press, 1979.

Schmuck, R.A., Runkel, P. J., \& Langmeyer, D. Improving organizational problem-solving in a school faculty. Journal of Applied Behavioral Science, 1969, 5, 455-482.

Shure, M.B., \& Spivack, G. Problem-solving techniques in childrearing. San Francisco: JosseyBass, 1978.

Spivack, G., \& Shure, M.B. Social adjustment of young children: A cognitive approach to solv: ing real-life problems. San Francisco: JosseyBass, 1974.

Stein, L. I., \& Test, M.A. (Ed5.). Alternarives to mental hospital treatment. New York: Plenum Press, 1978.

Szasz, T.S. The myth of mental illness. American Psychologist, $1960,15,113-118$.

Thoits, P.A. Conceptual, methodological, and theoretical problems in studying social support as a buffer against life stress. Journal of Health \& Social Bchavior, 1982, 23, 145-159.

Vachon, M.L.S., Lyall, W.A.L., Rogers, J., Freedman-Letofsky, K., \& Freeman, S.J.J, A controlled study of self-help intervention for widows. American Journal of Psychiatry, 1980. 137, 1380-1384,

Zubin, J., \& Spring, B. Vulnerability - A new view of schizophrenia. Journal of Abnormal Psychology, $1977,86,103-126$. 